\title{
Experimental Study on Effects of Particle Shape and Operating Conditions on Combustion Characteristics of Single Biomass Particles
}

Momeni, M.; Yin, Chungen; Kær, Søren Knudsen; Hansen, Troels Bruun; Jensen, Peter Arendt; Glarborg, Peter

Published in:

Energy \& Fuels

Publication date:

2013

Document Version

Publisher's PDF, also known as Version of record

Link back to DTU Orbit

Citation (APA):

Momeni, M., Yin, C., Kær, S. K., Hansen, T. B., Jensen, P. A., \& Glarborg, P. (2013). Experimental Study on Effects of Particle Shape and Operating Conditions on Combustion Characteristics of Single Biomass Particles. Energy \& Fuels, 27(1), 507-514. http://pubs.acs.org/doi/abs/10.1021/ef301343q

\section{General rights}

Copyright and moral rights for the publications made accessible in the public portal are retained by the authors and/or other copyright owners and it is a condition of accessing publications that users recognise and abide by the legal requirements associated with these rights.

- Users may download and print one copy of any publication from the public portal for the purpose of private study or research.

- You may not further distribute the material or use it for any profit-making activity or commercial gain

- You may freely distribute the URL identifying the publication in the public portal 


\title{
Experimental Study on Effects of Particle Shape and Operating Conditions on Combustion Characteristics of Single Biomass Particles
}

\author{
M. Momeni, ${ }^{* \dagger}$ C. Yin, ${ }^{* \dagger}$ S. K. Kær, ${ }^{\dagger}$ T. B. Hansen, ${ }^{\ddagger}$ P. A. Jensen, ${ }^{\ddagger}$ and P. Glarborg ${ }^{\ddagger}$ \\ ${ }^{\dagger}$ Department of Energy Technology, Aalborg University, DK-9220 Aalborg, Denmark \\ ${ }^{\ddagger}$ Department of Chemical Engineering, Technical University of Denmark, DK-2800 Lyngby, Denmark
}

\begin{abstract}
An experimental study is performed to investigate the ignition, devolatilization, and burnout of single biomass particles of various shapes and sizes under process conditions that are similar to those in an industrial combustor. A chargecoupled device (CCD) camera is used to record the whole combustion process. For the particles with similar volume (mass), cylindrical particles are found to lose mass faster than spherical particles and the burnout time is shortened by increasing the particle aspect ratio (surface area). The conversion times of cylindrical particles with almost the same surface area/volume ratio are very close to each other. The ignition, devolatilization, and burnout times of cylindrical particles are also affected by the oxidizer temperature and oxygen concentration, in which the oxygen concentration is found to have a more pronounced effect on the conversion times at lower oxidizer temperatures.
\end{abstract}

\section{INTRODUCTION}

Co-firing biomass with coal in existing power plants is an attractive option to significantly increase the share of renewable energy sources in an energy system and reduce $\mathrm{CO}_{2}$ emissions and has been successfully demonstrated in over 200 power plants globally. ${ }^{1}$ Nevertheless, fundamental combustion studies still must be performed to determine combustion characteristics in well-controlled conditions and finally to aid in the design and operation of the co-firing burners and boilers. ${ }^{2}$

Experimental studies of biomass combustion or biomass/coal co-firing in well-defined laboratory burner reactors have been reported in the literature, which mainly focus on the overall combustion characteristics of various biomass flames or cofiring flames. For instance, the share and injection mode of biomass and design and operation of burners were found to have significant effects on flame ignition, combustion aerodynamics, and $\mathrm{NO}_{x}$ emissions, ${ }^{3}$ on $\mathrm{NO}_{x}$ emissions, ${ }^{4}$ on flame structure and emissions, ${ }^{5,6}$ and on flame stability. ${ }^{7}$

There are also some fundamental studies with focus on reactivity and conversion of single biomass particles or biomass char. ${ }^{8-18}$ For instance, Wornat et al. experimentally studied the combustion reactivities of chars produced from the pyrolysis of woody and herbaceous biomass and found that the pine and switchgrass chars were quite reactive under conditions simulating pulverized fuel-fired boilers. Their burning rates were comparable to those of high-volatile bituminous coals at the early stages of char conversion and decreased to some extents during char conversion. ${ }^{12}$ Kuo and Hsi investigated the ignition of single wooden spheres heated in a hot air stream. The effects of the anisotropy of the thermal properties of the wood on its ignition time were found to be important, and different ignition modes (i.e., glowing ignition and flaming ignition) were observed. ${ }^{13} \mathrm{Lu}$ and $\mathrm{Lu}$ et al. studied the pyrolysis of large biomass particles $\left(d_{\mathrm{p}}=9.5 \mathrm{~mm}\right)$ in a nitrogen atmosphere at a fixed temperature and measured temperature profile and mass loss of single particles during pyrolysis. ${ }^{14,15}$ Jiménez et al. performed devolatilization and combustion experiments for pulverized biomass $(\sim 500 \mu \mathrm{m})$ in an entrained flow reactor under realistic combustion conditions, and useful Arrhenius parameters for the devolatilization and combustion processes were derived. ${ }^{16}$ Biagini et al. experimentally characterized the reactivity and morphology of biomass chars produced under high heating rates in a drop tube reactor. ${ }^{17}$ Karlström et al. determined reaction orders and kinetic parameters for the oxidation of five anthracite chars and one biomass char at temperatures ranging from 1223 to $1673 \mathrm{~K}$ using a multivariable optimization method, in which modeled burnout profiles were fitted to experimental data from a $4 \mathrm{~m}$ isothermal plug flow reactor operating under $10^{4}-10^{5} \mathrm{~K} / \mathrm{s}^{18}$

All of these experimental works provide very valuable insights into the overall combustion and emissions from biomass flames or co-firing flames, as well as the fundamental conversion and reactivity of single biomass or biomass char particles. However, the body of these fundamental characteristics of biomass particle conversion and biomass co-firing flames is still severely limited. Besides the great diversities in physical and chemical properties, raw biomass particles are often fibrous and nonfriable and, therefore, are difficult to be pulverized to the similar size as coal particles. As an example, the sizes and shapes of pulverized biomass particles for a commercial suspension cofiring can be seen in refs 19 and 20. The milled biomass particles are highly non-spherical, with the mean length over $15 \mathrm{~mm}$ and the maximum length over $100 \mathrm{~mm}$. Even though the more common way to prepare biomass for suspension co-firing in the latest retrofits (e.g., in Amager unit 1 in Denmark) may be to pelletize raw biomass first, then separately pulverize biomass pellets in traditional coal mills, and pneumatically transport to burners. The new process results in somewhat smaller

Received: August 17, 2012

Revised: November 14, 2012

Published: November 15, 2012 
biomass particles than the previous process. It still produces relatively large and non-spherical particles, with the maximum size up to a couple of millimeters, which need special attention in retrofitting and optimization of the original burners for cofiring. ${ }^{21,22}$

The objective of this experimental work is to further study the ignition, devolatilization, and burnout characteristics of small single biomass particles $(3.0 \mathrm{~mm})$ and to investigate the effects of the particle shape and surrounding conditions (oxidizer temperature and oxygen concentration) on the particle conversion.

\section{EXPERIMENTAL SECTION}

All of the experiments are conducted in a single particle combustion reactor, as shown in Figure 1. The setup is placed in the laboratory of

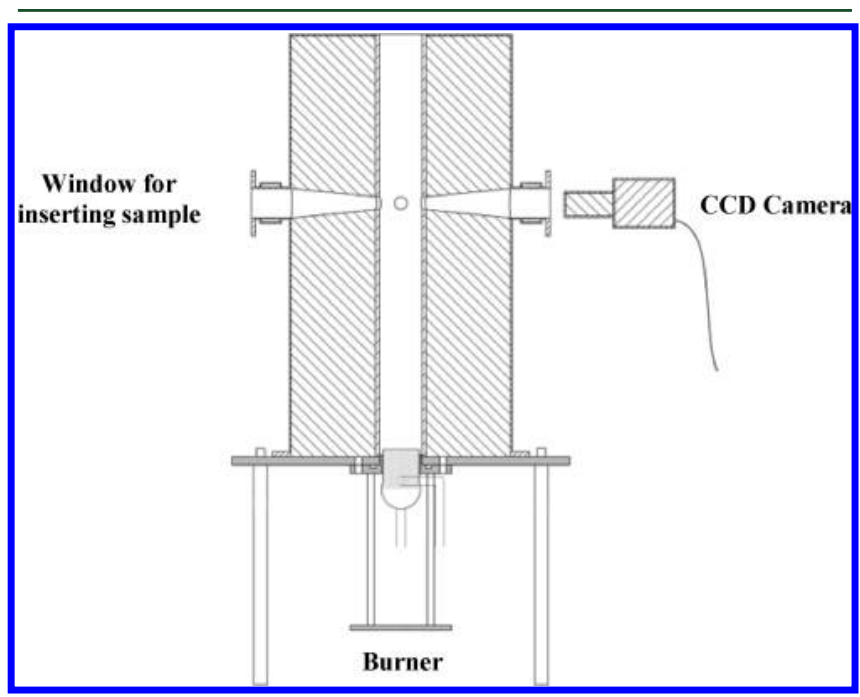

Figure 1. Schematic sketch of the experimental setup.

the CHEC group at the Technical University of Denmark, which mainly consists of a reactor, a burner, a safety system, and a gas supply system. The burner is a Blue Flame Technology 94 Jet Burner. A large amount of injection nozzles (94) and the flat profile of the burner result in a good mixture of gases, a good gas flow distribution through the reactor, and a reasonably flat temperature profile in the reactor center, where the biomass particles are placed. The flow rates are controlled by five mass flow controllers (MFCs) of the type EL-FLOW, which is connected to a computer. LabView 8.6 is used to controls the flow. The entire combustion process is recorded using a highperformance camera, which is an Allied Vision Technologies Stingray F-033 and is able to take 65 images per second on average. The frame rate can be increased or decreased by changing the resolution and shutter speed. The camera is connected to a computer, and the software AVT SmartView 1.11 is used to regulate and edit the camera settings. Then, the captured images are converted to an AVI video by Matlab script.

The biomass investigated in this study is pine wood, and its ultimate and proximate analysis data are listed in Table 1 . The wooden particles

Table 1. Chemical and Physical Properties of the Pine Wood

\begin{tabular}{lclc} 
proximate analysis (wt \%, as received) & \multicolumn{3}{c}{$\begin{array}{c}\text { ultimate analysis } \\
\text { (wt \%, as received) }\end{array}$} \\
moisture & 9.3 & $\mathrm{C}$ & 45.8 \\
volatiles & 77.4 & $\mathrm{H}$ & 5.95 \\
fixed carbon & 13 & $\mathrm{O}$ & 47.92 \\
ash & 0.3 & $\mathrm{~N}$ & 0.03 \\
lower heating value $(\mathrm{MJ} / \mathrm{kg})$ & 16.98 & density $\left(\mathrm{kg} / \mathrm{m}^{3}\right)$ & 600
\end{tabular}

are shaped into two groups: (1) sphere and various cylinders, all of which have the same mass or volume, and (2) various cylinders with the same diameter but different lengths. These particles and their dimensions can be better viewed from Figure 2 and Table 2. The gas temperature and oxygen concentration inside the reactor are in the range of $1200-1600{ }^{\circ} \mathrm{C}$ and $5-20 \%$, respectively. Under the participation of the local power industry, DONG Energy, the size range and shape of the wood particles and the heating rate and temperature levels in the reactor are selected to be very close to the realistic conditions in large pulverized wood-fired boilers.

The biomass particles can ignite very quickly. They would ignite even before reaching the reactor center, if it is directly inserted into the reactor without any insulation. Therefore, a ceramic protection tube is applied to cover the particle and allows it to reach the center before it is ignited. The tube is made of nonporous ceramic $\left(\mathrm{Al}_{2} \mathrm{O}_{3}\right)$, with a thermal conductivity of $30 \mathrm{~W} \mathrm{~m}^{-1} \mathrm{~K}^{-1}$. First of all, the ceramic protection tube is horizontally inserted into the reactor. Then, the particle, which is fixed with a $0.35 \mathrm{~mm}$ platinum wire through a hole drilled in the particle, is inserted into the protection tube from the opposite wall. After the protection tube is quickly withdrawn, the particle is immediately exposed to the hot gas and the experiment is initiated.

Figure 3 intuitively shows how the protection tube is removed and the particle is exposed to the hot flow, which also indicates how fast the procedure is performed $(\sim 0.033 \mathrm{~s})$. During this procedure, the heat transfer from the tube to the particle is negligible. Figure 4 shows how the temperature of a thermocouple placed inside the protection tube changes with time if the protection tube stays inside the reactor. It is evident that the temperature rise is very small in the first couple of seconds. As a comparison, the temperature of the thermocouple after the protection tube is quickly removed is also plotted in the dashed line in the figure. From these, one can clearly see that the particle combustion test is effectively started only after the protection tube is removed.

The temperature and oxygen profiles inside the reactor are measured by inserting a suction pyrometer and a suction probe into the reactor in the desired location from the wall to the reactor center. The measurements were conducted from both the left and right sides of the reactor. Because of the burner design, gas flow containing oxygen has more space at the outer radius inside the reactor, which, together with the heat loss to the surroundings, induces colder flow in the near-sidewall zones than in the reactor center. As an example of such measurements, Figure 5 shows the radial profiles of the temperature and oxygen concentration at the desired gas temperature and oxygen concentration $\left(1400{ }^{\circ} \mathrm{C}\right.$ and 3 vol \%, respectively) in the center of the reactor.

\section{RESULTS AND DISCUSSION}

Wooden particle combustion data are collected as video sequences in the single particle reactor at different conditions. A few tests are repeated 3-5 times to ensure the repeatability of the tests and the reliability of the results.

3.1. Determination of Ignition, Devolatilization, and Burnout Times. Three different times can be estimated from the videos: ignition time, total devolatilization time, and burnout time. The criteria for determining the ignition, devolatilization, and burnout times are based on the observation from the images captured during the whole combustion process. Initial time $\left(t_{0}\right)$ always corresponds to the removal of the protection tube. It is assumed that the ignition time is when the first flame is observed from the images. After the ignition, the visible devolatilization process is started and the flame around the particle becomes obvious during this period. When the flame disappears, it is assumed that devolatilization has finished and the time is recorded as the devolatilization process time. Then, the remaining char is combusted without an obvious flame. The char burning is continued until the complete burnout. At this 


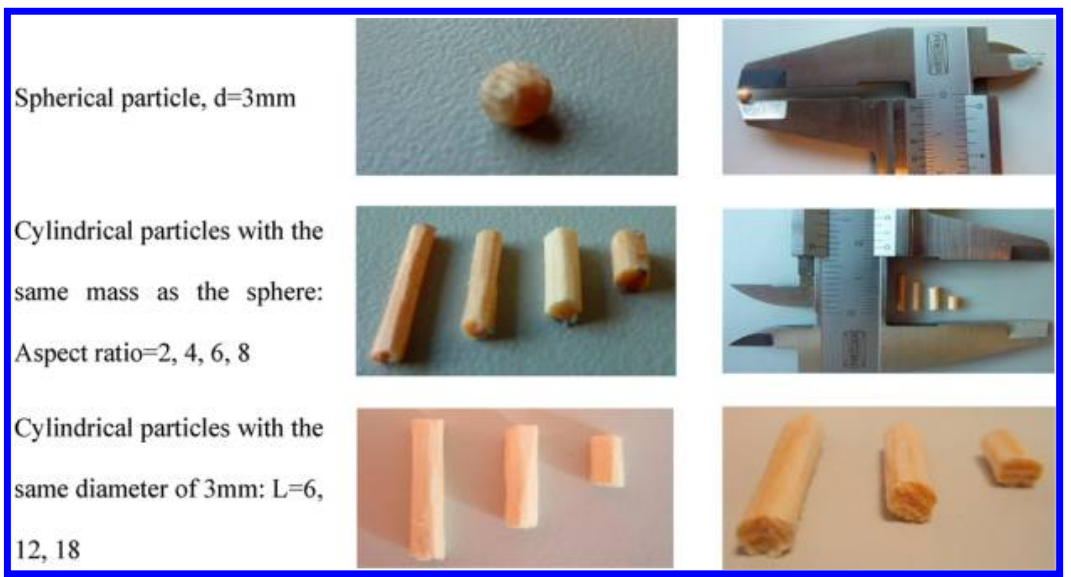

Figure 2. Samples of some of the tested biomass particles.

Table 2. Size and Shape Information of the Sample

\begin{tabular}{lccccc} 
shape & $\begin{array}{c}d \\
(\mathrm{~mm})\end{array}$ & $\begin{array}{c}L \\
(\mathrm{~mm})\end{array}$ & $\begin{array}{c}\text { aspect } \\
\text { ratio, } L / d\end{array}$ & mass $(\mathrm{g})$ & $\begin{array}{c}\text { surface area/volume, } \\
S / V\left(\mathrm{~mm}^{-1}\right)\end{array}$ \\
sphere & 3.0 & & 1 & $\approx 0.0125$ & 2.0 \\
cylinder & 2.08 & 4.16 & 2 & $\approx 0.0125$ & 2.4 \\
cylinder & 1.65 & 6.60 & 4 & $\approx 0.0125$ & 2.7 \\
cylinder & 1.44 & 8.65 & 6 & $\approx 0.0125$ & 3.0 \\
cylinder & 1.31 & 10.48 & 8 & $\approx 0.0125$ & 3.2 \\
cylinder & 3.0 & 6 & 2 & 0.0230 & 1.6 \\
cylinder & 3.0 & 12 & 4 & 0.0490 & 1.5 \\
cylinder & 3.0 & 18 & 6 & 0.0695 & 1.4 \\
\hline
\end{tabular}

moment, no remarkable particle shrinkage is observed and only ash is left in the particle. Because the char-burning process may overlap with the devolatilization process, determining the char burnout time from the images could be underestimated. Hence, in this study, the total time, from inserting the particle into the reactor to the end of the combustion process, is referred to as the burnout time.

Figure 6 illustrates via an example how the three conversion times are estimated from the images taken for a cylindrical particle, from which $0.0549,3.0862$, and $8.2262 \mathrm{~s}$ are determined as the ignition time, devolatilization time, and burnout time, respectively. For instance, for devolatilization, the flame vanishes just at $3.0972 \mathrm{~s}$. Therefore, the previous time, $3.0862 \mathrm{~s}$, is taken as the end of the devolatilization process.

3.2. Effects of Particle Shapes on Ignition, Devolatilization, and Burnout Times. When the protection tube is removed, the biomass particle will be suddenly exposed to hot air flow and undergo a series of conversion processes: heating,

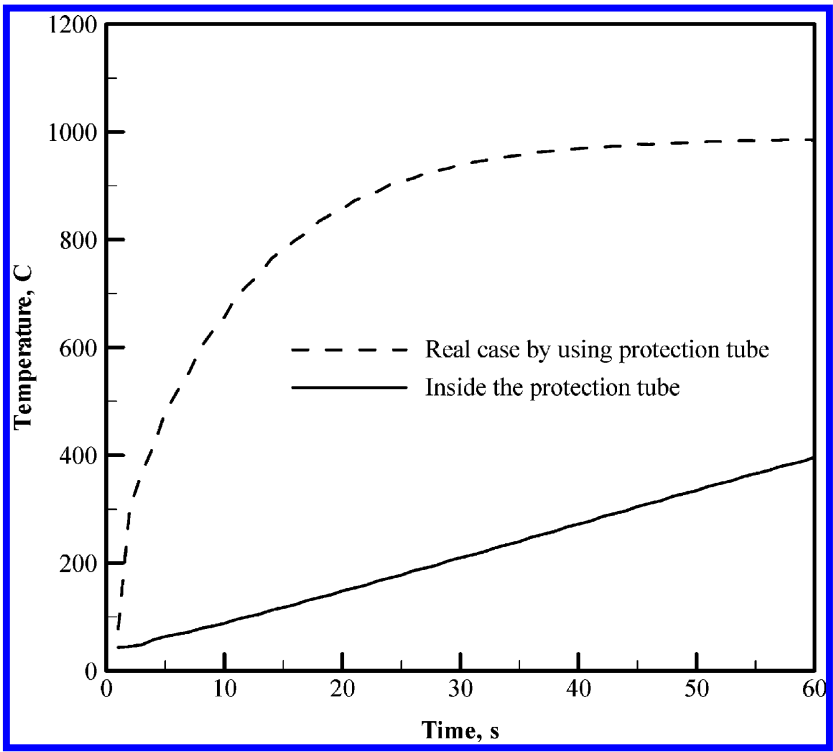

Figure 4. Evolution of the thermocouple (or particle) temperature along with time in the protection tube and reactor.

moisture evaporation, release and combustion of volatiles, and heterogeneous oxidation of biomass char. The temperature and mass of the particle in the various processes may be updated as follows:

heating:

$$
m_{\mathrm{p}} C_{\mathrm{p}} \frac{\mathrm{d} T_{\mathrm{p}}}{\mathrm{d} t}=h A_{\mathrm{p}}\left(T_{\mathrm{g}}-T_{\mathrm{p}}\right)+\varepsilon_{\mathrm{p}} A_{\mathrm{p}} \sigma\left(\theta_{\mathrm{R}}^{4}-T_{\mathrm{p}}^{4}\right)
$$

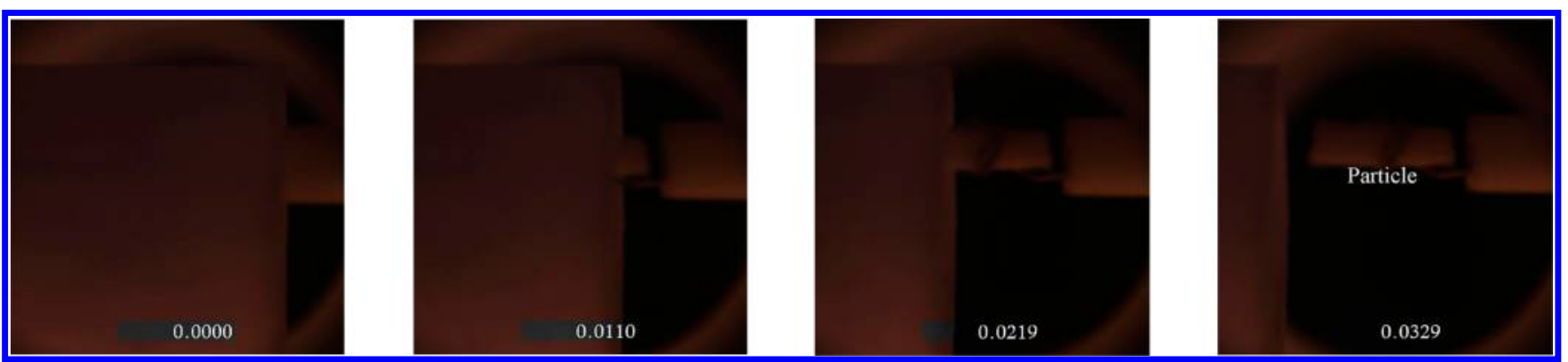

Figure 3. Removing the protection tube from the left to the right: at $t=0.000 \mathrm{~s}$, the cylindrical particle is entirely covered by the tube; at $t=0.0329 \mathrm{~s}$, the cylindrical particle is entirely exposed to the hot flow in the reactor. 


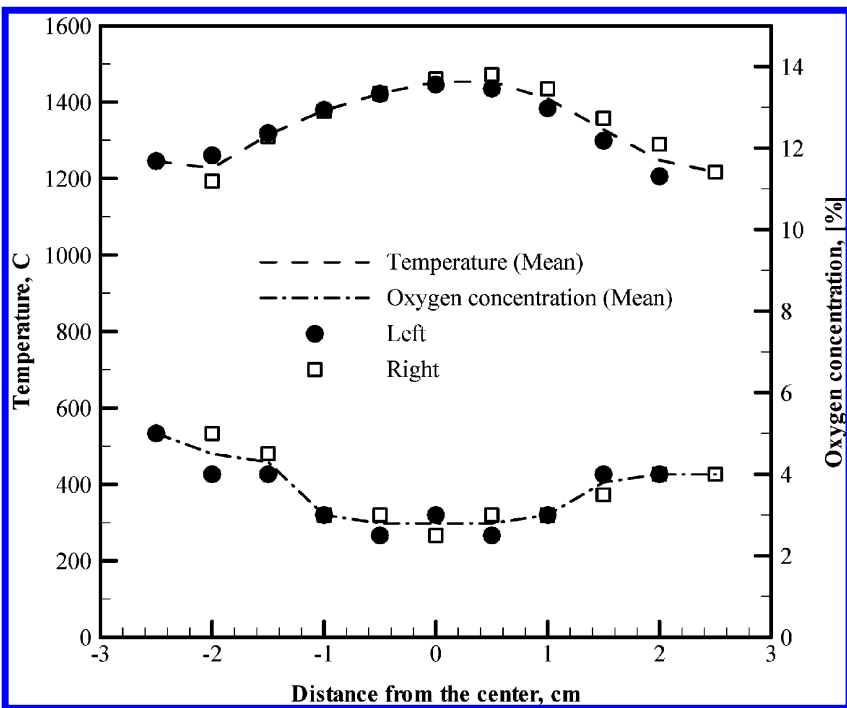

Figure 5. Measured temperature and oxygen profiles under desired conditions $\left(T_{\text {center }}=1400{ }^{\circ} \mathrm{C} ; \mathrm{O}_{2, \text { center }}=3 \%\right)$.

evaporation: $\left\{\begin{array}{l}\frac{\mathrm{d} m_{\mathrm{p}}}{\mathrm{d} t}=-N_{\text {vap }} A_{\mathrm{p}} \mathrm{MW}_{\text {vap }} \\ m_{\mathrm{p}} C_{\mathrm{p}} \frac{\mathrm{d} T_{\mathrm{p}}}{\mathrm{d} t}=h A_{\mathrm{p}}\left(T_{\mathrm{g}}-T_{\mathrm{p}}\right)+\frac{\mathrm{d} m_{\mathrm{p}}}{\mathrm{d} t} H_{\text {evap }} \\ +\varepsilon_{\mathrm{p}} A_{\mathrm{p}} \sigma\left(\theta_{\mathrm{R}}{ }^{4}-T_{\mathrm{p}}{ }^{4}\right)\end{array}\right.$

devolatilization:

$$
\left\{\begin{array}{l}
\frac{\mathrm{d} m_{\mathrm{p}}}{\mathrm{d} t}=-k\left(m_{\mathrm{p}}-\left(1-f_{\mathrm{v}_{0}}\right) m_{\mathrm{p}_{\mathrm{o}}}\right) \\
m_{\mathrm{p}} C_{\mathrm{p}} \frac{\mathrm{d} T_{\mathrm{p}}}{\mathrm{d} t}=h A_{\mathrm{p}}\left(T_{\mathrm{g}}-T_{\mathrm{p}}\right)+\frac{\mathrm{d} m_{\mathrm{p}}}{\mathrm{d} t} H_{\mathrm{fg}} \\
\quad+\varepsilon_{\mathrm{p}} A_{\mathrm{p}} \sigma\left(\theta_{\mathrm{R}}^{4}-T_{\mathrm{p}}^{4}\right)
\end{array}\right.
$$

char oxidation:

$$
\left\{\begin{array}{l}
\frac{\mathrm{d} m_{\mathrm{p}}}{\mathrm{d} t}=-4 \pi d_{\mathrm{p}} D_{\mathrm{ox}} \frac{Y_{\mathrm{ox}} \rho_{\mathrm{f}} T_{\mathrm{g}}}{S_{\mathrm{b}}\left(T_{\mathrm{p}}+T_{\mathrm{g}}\right)} \phi_{\mathrm{en}} \\
\quad(\text { diffusion-limited for large particles }) \\
m_{\mathrm{p}} C_{\mathrm{p}} \frac{\mathrm{d} T_{\mathrm{p}}}{\mathrm{d} t}=h A_{\mathrm{p}}\left(T_{\mathrm{g}}-T_{\mathrm{p}}\right)-f_{\mathrm{h}} \frac{\mathrm{d} m_{\mathrm{p}}}{\mathrm{d} t} H_{\text {reac }} \\
\quad+\varepsilon_{\mathrm{p}} A_{\mathrm{p}} \sigma\left(\theta_{\mathrm{R}}{ }^{4}-T_{\mathrm{p}}{ }^{4}\right)
\end{array}\right.
$$

In the heating equations, $m_{\mathrm{p}}, C_{\mathrm{p}}, T_{\mathrm{p}}, t, h, A_{\mathrm{p}}, T_{\mathrm{g}}, \varepsilon_{\mathrm{p}}, \sigma$, and $\theta_{\mathrm{R}}$ represent the particle mass, particle specific heat, particle temperature, time, convective heat-transfer coefficient, particle surface area, local gas temperature at the particle position, particle emissivity, Stefan-Boltzmann constant, and radiation temperature, respectively. In evaporation, $N_{\text {vap }}, \mathrm{MW}_{\text {vap}}$, and $H_{\text {evap }}$ are the molar flux of moisture vapor, molecular weight of moisture vapor, and heat of evaporation, respectively. In devolatilization, $k, f_{\mathrm{vo}^{\prime}} m_{\mathrm{po}^{0^{\prime}}}$ and $H_{\mathrm{fg}}$ stand for the kinetic rate of devolatilization, mass fraction of the volatiles that are initially present in the particle, initial particle mass, and latent heat of the particle (which is often negligible), respectively. In char oxidation, $D_{\mathrm{ox}}, Y_{\mathrm{ox}}, S_{\mathrm{b}}, H_{\text {reac }}, f_{\mathrm{h}}$ and $\phi_{\mathrm{en}}$ denote the diffusion

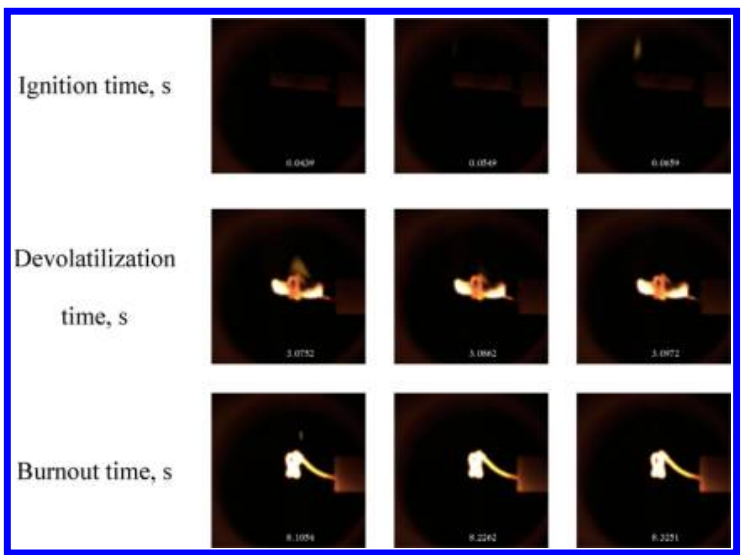

Figure 6. Selected images of the spherical particle at the different stages.

coefficient of oxygen in the bulk gas, local mass fraction of oxygen in the gas, stoichiometry of the reaction $1 \mathrm{~kg}$ of $\mathrm{C}(\mathrm{s})+$ $S_{\mathrm{b}} \mathrm{kg}$ of $\mathrm{O}_{2} \rightarrow\left(1+S_{\mathrm{b}}\right) \mathrm{kg}$ of $\mathrm{CO}_{x}$ defined in terms of the mass of oxygen per mass of char, heat released by the surface reaction, fraction of the heat absorbed by the particle, and enhancement factor because of non-sphericity, respectively. ${ }^{19}$

From eqs 1-4, one can see that, the larger the surface area/ volume ratio, the faster the particle will be heated and, therefore, the faster the conversion process. Evaporation is an endothermic reaction. When moisture is driven off of the particle, the large evaporation heat needed may offset to some extents the faster temperature rise. Therefore, the particle shape may be expected to have less of a remarkable effect on the ignition process than devolatilization and char oxidation or more precisely have less of a remarkable effect on the temperature rise before the moisture is completely driven off.

Figure 7 compares the conversion characteristics of the five biomass particles that have the same volume (or mass): one spherical particle and four cylindrical particles (aspect ratios of 2, 4, 6, and 8). All of the three main processes (ignition, devolatilization, and burnout) are affected by the particle shape but with different intensities. As shown in Table 2, for the particles having the same volume, the spherical particles have the smallest surface area/volume ratio. The surface area/ volume ratio will increase with the aspect ratio for cylindrical particles. Therefore, the particles with a larger aspect ratio will be heated by the external convection and radiation faster, resulting in a faster conversion rate. For ignition, the experimental observation shows a similar trend but not as remarkable as the effects on devolitilization and burnout. The ignition time is reduced from $0.1 \mathrm{~s}$ for the spherical particle to $0.04 \mathrm{~s}$ for the cylindrical particle with the largest aspect ratio. All of the experimental observations are very well in line with the theoretical expectations, as pointed out above.

Because the ignition time for all particles is very short and the devolatilization time varies in a relatively small interval compared to the burnout time, it can be concluded that the heterogeneous reactions on the particle surface (char burning) are affected by the particle shape (surface area) much more than the other processes (ignition and devolatilization). Combustion tests of spherical and cylindrical particles with aspect ratios of 2 and 6 are repeated 3-5 times, and the results (as shown in Figure 7) exhibit good repeatability.

Figure 8 compares the devolatilization and burnout times of the four biomass particles that have the same diameter $(3 \mathrm{~mm})$ 


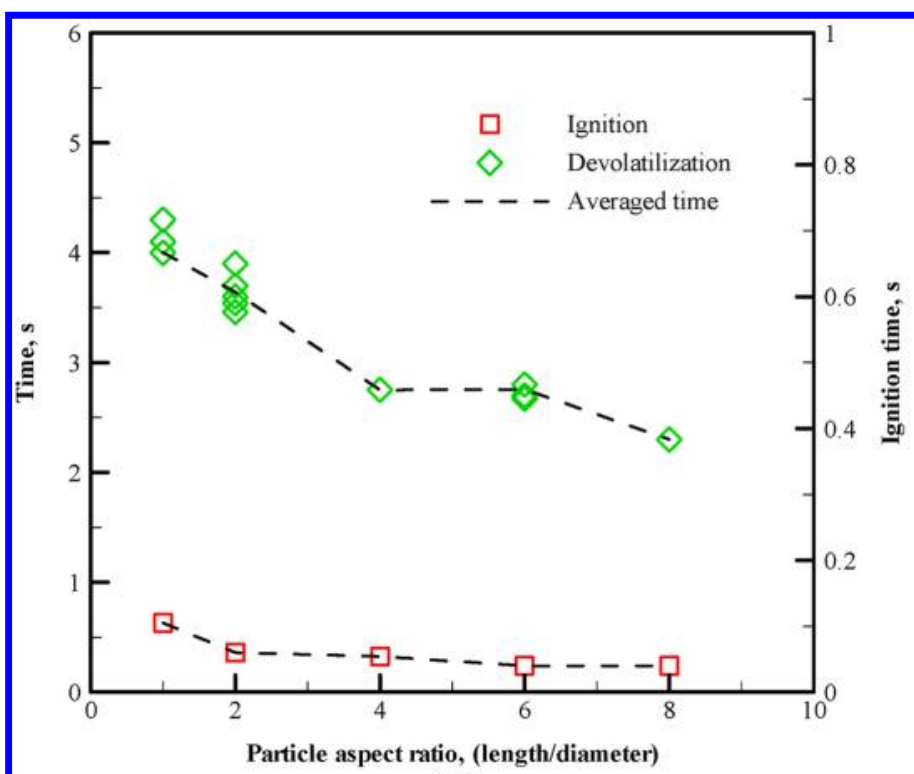

(a)

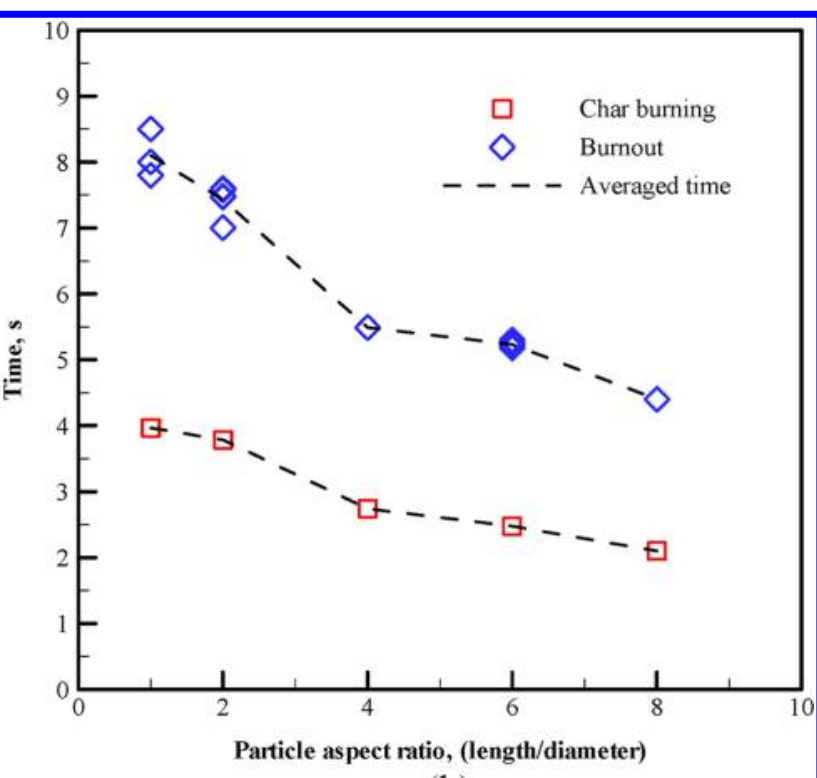

(b)

Figure 7. Ignition, devolatilization, char burning, and total burnout times of particles with the same mass (or volume) but different aspect ratios $\left(\mathrm{AR}=1\right.$ for spherical particle) under process conditions of $T=1200{ }^{\circ} \mathrm{C}$ and $\mathrm{O}_{2}=20 \%$.

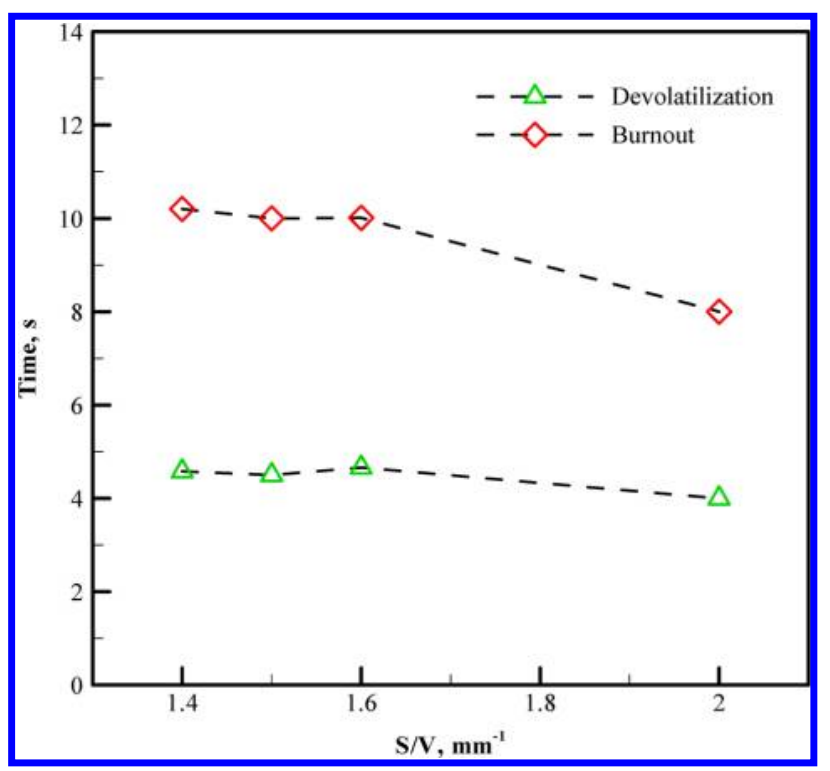

Figure 8. Devolatilization and burnout times of particles with the same diameter $(3 \mathrm{~mm})$ but different lengths (or volumes) under process conditions of $\mathrm{T}=1200{ }^{\circ} \mathrm{C}$ and $\mathrm{O}_{2}=20 \%$.

but different lengths (or volumes): one spherical particle and three cylindrical particles (with lengths of 6,12 , and $18 \mathrm{~mm}$ ). As seen in Table 2, the surface area/volume ratios of the three cylindrical particles are nearly the same (all about 1.5) and the surface area/volume of the sphere is slightly high (about 2.0). Therefore, the spherical particle is expected to have a slightly faster conversion than the cylindrical particles, while the three cylindrical particles would have very similar conversion rates. The experimental results shown in Figure 8 well confirm these trends.

3.3. Effects of Surrounding Conditions on Ignition, Devolatilization, and Burnout Times. The conversion characteristics of the cylindrical particle $(d=1.65 \mathrm{~mm}$, $L=6.60 \mathrm{~mm}$, and aspect ratio of 4) under different surrounding conditions are investigated. The temperatures vary from 1200 to $1600{ }^{\circ} \mathrm{C}$, and oxygen concentrations are in the range of $5-20 \%$. Figure 9 illustrate the effects of the oxidizer

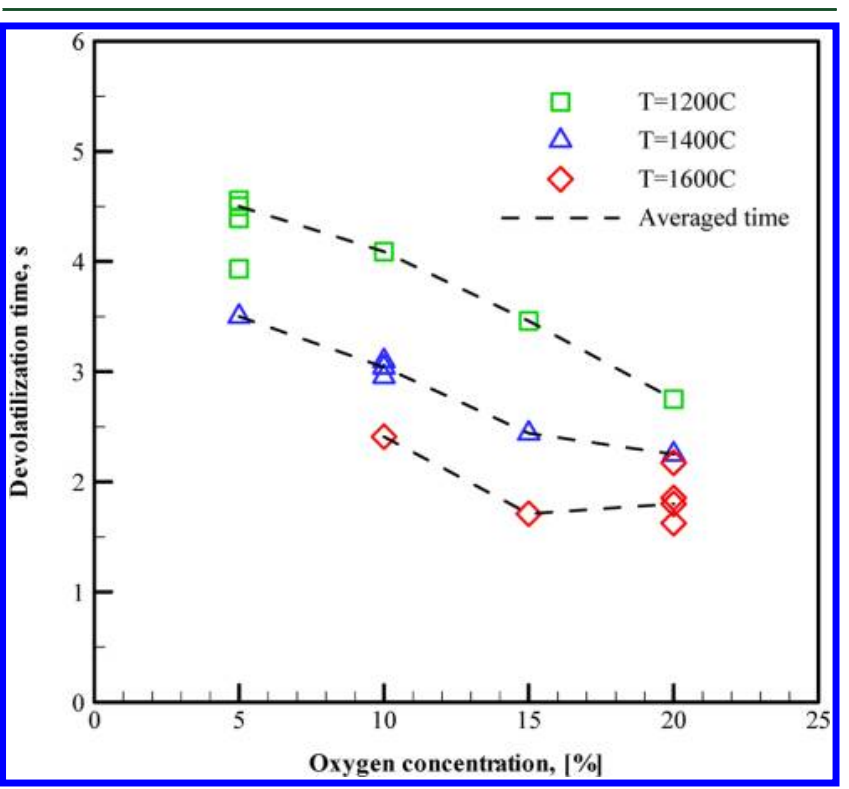

Figure 9. Effects of process conditions on devolatilization of a cylindrical particle $(d=1.65 \mathrm{~mm}, L=6.60 \mathrm{~mm}$, and aspect ratio of 4$)$.

temperature and oxygen concentration on the particle devolatilization time.

Here, it has to be restated that, in this study, the devolatilization time is defined as the time interval from inserting the particle to the reactor to the moment that all of the volatiles are combusted in this study. Increasing the oxygen concentration will speed up homogeneous combustion of the released volatiles and, in turn, intensify the local heat release. Therefore, higher oxygen concentrations are expected to remarkably shorten the devolatilization time. 
For heterogeneous oxidation of biomass char, different modes or zones exist. In general, the net combustion rate can be estimated as

$$
\dot{m}_{\mathrm{C}}=\frac{Y_{\mathrm{O}_{2}, \infty}}{R_{\text {diff }}+R_{\text {kin }}}
$$

where $Y_{\mathrm{O}_{2}, \infty}, R_{\text {diff, }}$ and $R_{\text {kin }}$ represent the mass fraction of oxygen in the bulk gas flow around the particle, external diffusion resistance, and internal kinetic resistance, respectively. For a large particle size and high particle temperature, the diffusion resistance will be the limited factor, while for a small particle size and low particle temperature, the kinetic resistance will dominate. Assuming that the particle and local gas are at thermal equilibrium conditions (i.e., $T_{\mathrm{p}} \approx T_{\mathrm{g}}$ ) and no oxygen is available at the particle surface $\left(Y_{\mathrm{O}_{2}, \mathrm{~s}}=0\right)$, the diffusion resistance can be derived from eq 5 as follows:

$$
R_{\text {diff }}=\frac{S_{\mathrm{b}}}{4 \pi r_{\mathrm{p}} D_{\mathrm{ox}} \rho_{\mathrm{f}}}
$$

The chemical kinetic resistance can be evaluated from

$$
R_{\mathrm{kin}}=\frac{S_{\mathrm{b}} R_{\mathrm{u}} T_{\mathrm{p}}}{4 \pi r_{\mathrm{p}}{ }^{2} \mathrm{MW}_{\text {mix }} \frac{1}{3} r_{\mathrm{p}} k P}
$$

Here, an equivolume sphere with a radius of $r_{\mathrm{p}}$ is used to represent the cylindrical particle in this estimation. The temperature-dependent mass diffusivity is $D_{\mathrm{ox}}=1.6 \times 10^{-5}$ $\left(T_{\mathrm{g}} / 393\right)^{1.5}$. The local fluid density, $\rho_{\mathrm{f}}$ is evaluated by the ideal gas law, from the local gas temperature $T_{\mathrm{g}}$ and pressure $P(=101$ $325 \mathrm{~Pa})$. For a char particle burning in air under the typical temperature range as met in commercial boilers and furnaces, the main reaction is widely believed to be partial oxidation of char into $\mathrm{CO}^{23}$ as shown in eq 8 .

$$
1 \mathrm{~kg} \text { of } \mathrm{C}+S_{\mathrm{b}} \mathrm{kg} \text { of } \mathrm{O}_{2} \rightarrow\left(S_{\mathrm{b}}+1\right) \mathrm{kg} \text { of } \mathrm{CO}
$$

Therefore, $S_{\mathrm{b}}=1.332$ is used in both eqs 6 and 7. To reliably interpret the burnout in this study, the kinetic data of char from the same wood produced under the same thermal conditions in a similar reactor are used to calculate the kinetic rate $k$ in eq 7 .

Dall'Ora et al. investigated the reactivity of the chars from pine, produced by fast pyrolysis (heating rate of $10^{4}-10^{5} \mathrm{~K} / \mathrm{s}$ ), in an entrained flow reactor in the temperature range of 873$1573 \mathrm{~K}^{24}$ The oxidation kinetics of the chars was derived from experimental mass loss data according to a volumetric reaction model assuming a single first-order reaction based on the instantaneous char weight

$$
\text { kinetic rate, } \quad k=-\frac{1}{m} \frac{\mathrm{d} m}{\mathrm{~d} t}=A \mathrm{e}^{-E_{\mathrm{a}} / R_{\mathrm{u}} T}
$$

To compare the reactivity of different chars, a common activation energy $E_{\mathrm{a}}$ was used for all of the chars $\left(E_{\mathrm{a}}=166\right.$ $\mathrm{kJ} / \mathrm{mol}$, or $\left.E_{\mathrm{a}} / R_{\mathrm{u}}=20000 \mathrm{~K}\right)$ and the pre-exponential factor $A$ was the only parameter to be derived. Char reactivity was found to decrease as the pyrolysis temperature increased, because of the well-known "thermal deactivation" phenomenon. At higher temperatures, the carbon matrix in char attains a more ordered, graphite-like structure and, therefore, loses active sites. For instance, the reactivity of the chars from pine produced by fast pyrolysis decreased by 2 orders of magnitude when the pyrolysis temperature was raised from 1273 to $1573 \mathrm{~K}$; i.e.,
$A \approx 1.1 \times 10^{10}$ and $1.1 \times 10^{8} \mathrm{~s}^{-1}$ for the two temperatures, respectively.

Here, the pre-exponential factor and activation energy $(A \approx$ $1.1 \times 10^{8} \mathrm{~s}^{-1}$, and $\left.E_{\mathrm{a}} / R_{\mathrm{u}}=20000 \mathrm{~K}\right)^{24}$ are employed in the calculation of the kinetic rate of char oxidation in this study (temperature in range of $1473-1873 \mathrm{~K}$ ), which is then used to evaluate the chemical kinetic resistance $R_{\text {kin }}$. The relative strength of the chemical kinetic resistance to the diffusion resistance for the pine char oxidation under the conditions in this experimental study is plotted in Figure 10. The two

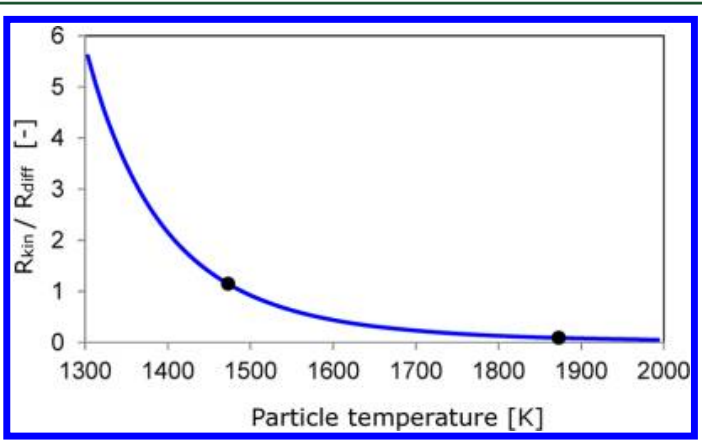

Figure 10. Relative strength of chemical kinetic resistance to diffusion resistance during oxidation of the char particle from pine wood produced by fast pyrolysis (equivolume sphere diameter of $3 \mathrm{~mm}$ ).

resistances are found to be at the same order at $1473 \mathrm{~K}$, while the chemical resistance can be neglected when the temperature is raised to $1873 \mathrm{~K}$, both of which are dotted in Figure 10 .

Increasing the oxygen concentration in the bulk flow will always remarkably speed up the char oxidation process, as expected from eq 4, which is also observed from the experimental results in Figure 11. At comparatively low

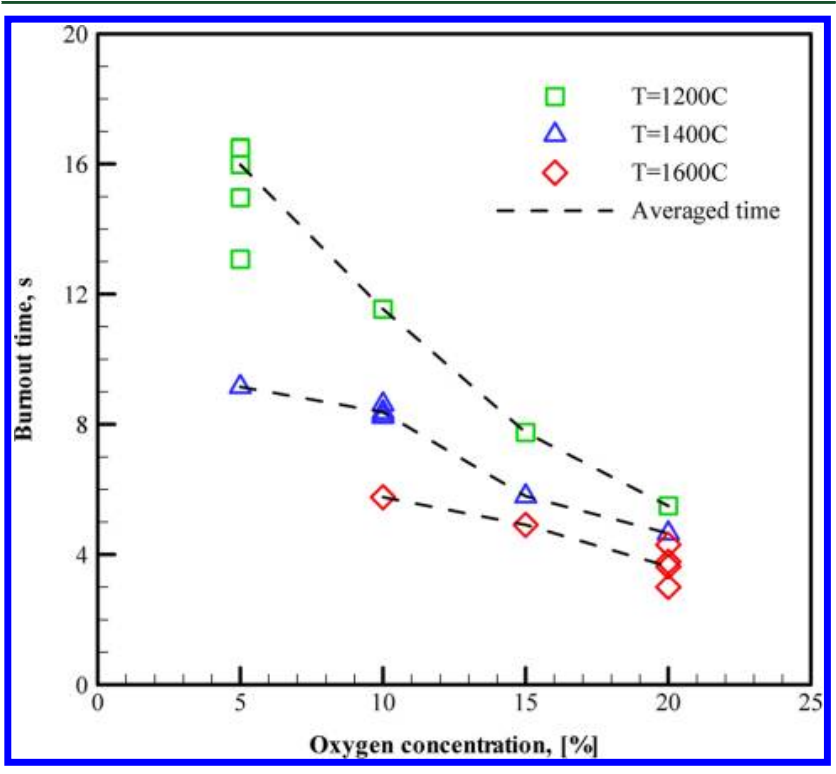

Figure 11. Effects of process conditions on burnout of a cylindrical particle $(d=1.65 \mathrm{~mm}, L=6.60 \mathrm{~mm}$, and aspect ratio of 4$)$.

temperatures (e.g., $T=1473 \mathrm{~K}$ or $1200{ }^{\circ} \mathrm{C}$, in Figure 11), the kinetic resistance $R_{\text {kin }}$ also plays an important role, as indicated in Figure 10. Under this temperature, an increase in the oxygen concentration may have double effects. First, it will intensify the char oxidation, as it always does. Second, the 
enhanced char oxidation (as well as the enhanced volatile combustion) will, in turn, intensify the heat release around the particle and remarkably increase the particle temperature to higher levels, so that the kinetic resistance $R_{\text {kin }}$ becomes negligible. Therefore, the effect of the increase in the oxygen concentration is expected to be more pronounced at low temperatures than at high temperatures. In the latter, the kinetic resistance $R_{\text {kin }}$ is always negligible. Such an expectation is also very well reproduced from this experimental study.

Such an effect of oxygen concentrations on char burnout at different temperatures may be directly reflected from the effective reaction rate of solid carbon oxidation, without explicitly distinguishing various combustion modes or zones. The carbon oxidation rate in the reaction shown in eq $10, R_{s}$, is most commonly represented as an arbitrary ( $n$ th) power of the oxygen molar fraction, $x_{\mathrm{O}_{2}}{ }^{25,26}$

$$
R_{\mathrm{s}}=k x_{\mathrm{O}_{2}}{ }^{n}
$$

The effective reaction "order" increases from zero at low temperatures (below $500{ }^{\circ} \mathrm{C}$ ) to unity at high temperatures (above $2000{ }^{\circ} \mathrm{C}$ ). The effective reaction "order" is about 0.5 and 0.7 at temperatures of 1200 and $1600{ }^{\circ} \mathrm{C}$, respectively. ${ }^{25}$ Therefore, one can expect a slightly more pronounced effect of the oxygen concentration on the burnout times at $1200{ }^{\circ} \mathrm{C}$ than at $1600{ }^{\circ} \mathrm{C}$, when the oxygen concentration increases from 5 to $20 \%$.

\section{CONCLUSION}

The experimental observations and data obtained at very high temperatures not only shed light on the in-depth understanding of single biomass conversion under similar process conditions as in large pulverized wood-fired boilers but also provide valuable inputs for modeling and simulation validation. Some specific conclusions can be drawn as follows.

Among various biomass particles with similar volume (or mass), spherical particles have the longest conversion time because of the fact that they have the lowest surface area/ volume ratio. Highly non-spherical particles favor a fast and complete conversion, provided sufficient residence times.

From a practical point of view, biomass particles prepared for co-firing in power plants are more likely to have a similar diameter (rather than similar mass) and different lengths. For such particles, spherical particles have the highest surface area/ volume ratio and favor a fast and complete burnout. For cylindrical particles of different lengths, their conversion characteristics are more or less similar because of the similar surface area/volume ratio.

An increase in the gas temperature and oxygen concentration favors all of the sub-processes during biomass combustion, among which the effect of the oxygen concentration on char oxidation is more pronounced at comparatively low temperatures than at high temperatures.

\section{AUTHOR INFORMATION}

\section{Corresponding Author}

*Telephone: +45-99409276. Fax: +45-98151411. E-mail: mam@et.aau.dk (M.M.); chy@et.aau.dk (C.Y.).

\section{Notes}

The authors declare no competing financial interest.

\section{ACKNOWLEDGMENTS}

This work was financially supported by DONG Energy. The authors thank Søren Lovmand Hvid for his valuable comments and Paw Jensen for his help in performing the experiments.

\section{REFERENCES}

(1) International Energy Agency (IEA). Biomass Co-firing Database, Task 32 of the IEA Bioenergy Agreement; http://www.ieabcc.nl/ database/cofiring.php (accessed Oct 18, 2012).

(2) Sami, M.; Annamalai, K.; Wooldridge, M. Co-firing of coal and biomass fuel blends. Prog. Energy Combust. Sci. 2001, 27, 171-214.

(3) Abbas, T.; Costen, P.; Kandamby, N. H.; Lockwood, F. C.; Ou, J. $\mathrm{J}$. The influence of burner injection mode on pulverized coal and biomass cofired flames. Combust. Flame 1994, 99, 617-625.

(4) Spliethoff, H.; Hein, K. R. G. Effect of co-combustion of biomass on emissions in pulverized fuel furnaces. Fuel Process. Technol. 1998, 54, 189-205.

(5) Damstedt, B.; Pedersen, J. M.; Hansen, D.; Knighton, T.; Jones, J.; Christensen, C.; Baxter, L.; Tree, D. Biomass cofiring impacts on flame structure and emissions. Proc. Combust. Inst. 2007, 31, 28132820.

(6) Damstedt, B. Structure and nitrogen chemistry in coal, biomass and cofiring in low-NO $\mathrm{N}_{x}$ flames. Ph.D. Thesis, Brigham Young University, Provo, UT, 2007.

(7) Lu, G.; Yan, Y.; Cornwell, S.; Whitehousem, M.; Riley, G. Impact of co-firing coal and biomass on flame characteristics and stability. Fuel 2008, 87, 1133-1140.

(8) Liliedahl, T.; Sjöström, K. Heat transfer controlled pyrolysis kinetics of a biomass slab, rod or sphere. Biomass Bioenergy 1998, 15, 503-509.

(9) Di Blasi, C.; Buonanno, F.; Branca, C. Reactivities of some biomass chars in air. Carbon 1999, 37, 1227-1238.

(10) Yang, Y. B.; Sharifi, V. N.; Swithenbank, J.; Ma, L.; Darvell, L. I.; Jones, J. M.; Pourkashanian, M.; Williams, A. Combustion of a single particle of biomass. Energy Fuels 2008, 22, 306-316.

(11) Saastamoinen, J.; Aho, M.; Moilanen, A.; Sørensen, L. H.; Clausen, S.; Berg, M. Burnout of pulverized biomass particles in large scale boiler-Single particle model approach. Biomass Bioenergy 2010, $34,728-736$.

(12) Wornat, M. J.; Hurt, R. H.; Davis, K. A.; Yang, N. C. Singleparticle combustion of two biomass chars. Symp. (Int.) Combust., [Proc.] 1996, 3075-3083.

(13) Kuo, J. T.; Hsi, C. L. Pyrolysis and ignition of single wooden spheres heated in high-temperature streams of air. Combust. Flame 2005, 142, 401-412.

(14) Lu, H.; Robert, W.; Peirce, G.; Ripa, B.; Baxter, L. L. Comprehensive study of biomass particle combustion. Energy Fuels 2008, 22, 2826-2839.

(15) $\mathrm{Lu}, \mathrm{H}$. Experimental and modeling investigations of biomass particle combustion. PhD Thesis, Brigham Young University, Provo, UT, 2006

(16) Jiménez, S.; Remacha, P.; Ballesteros, J. C.; Giménez, A.; Ballester, J. Kinetics of devolatilization and oxidation of a pulverized biomass in an entrained flow reactor under realistic combustion conditions. Combust. Flame 2008, 152, 588-603.

(17) Biagini, E.; Simone, M.; Tognotti, L. Characteristics of high heating rate chars of biomass fuels. Proc. Combust. Inst. 2009, 32, 2043-2050.

(18) Karlström, O.; Brink, A.; Biagini, E.; Hupa, M.; Tognotti, L. Comparing reaction orders of anthracite chars with bituminous coal chars at high temperature oxidation conditions. Proc. Combust. Inst. 2012, DOI: $10.1016 /$ j.proci.2012.07.011.

(19) Yin, C.; Rosendahl, L.; Kær, S. K.; Condra, T. Use of numerical modeling in design for co-firing biomass in wall-fired burners. Chem. Eng. Sci. 2004, 59, 3281-3292.

(20) Rosendahl, L.; Yin, C.; Kær, S. K.; Friborg, K.; Overgaard, P. Physical characterization of biomass fuels prepared for suspension 
firing in utility boilers for CFD modelling. Biomass Bioenergy 2007, 31, $318-325$.

(21) Mandø, M.; Rosendahl, L.; Yin, C.; Sørensen, H. Pulverized straw combustion in a low- $\mathrm{NO}_{x}$ multifuel burner: Modeling the transition from coal to straw. Fuel 2010, 89, 3051-3062.

(22) Yin, C.; Kær, S. K.; Rosendahl, L.; Hvid, S. L. Co-firing straw with coal in a swirl-stabilized dual-feed burner: Modeling and experimental validation. Bioresour. Technol. 2010, 101, 4169-4178.

(23) Hurt, R. H.; Calo, J. M. Semi-global kinetics for char combustion modeling. Combust. Flame 2001, 125, 1138-1149.

(24) Dall'Ora, M.; Jensen, P. A.; Jensen, A. D. Suspension combustion of wood: Influence of pyrolysis conditions on char yield, morphology, and reactivity. Energy Fuels 2008, 22, 2955-2962.

(25) Klimesh, H. E.; Essenhigh, R. H. Non-dissociative and dissociative adsorption of oxygen on carbon: A theoretical comparison with prediction of reaction order. Symp. (Int.) Combust., [Proc.] 1998, 2941-2948.

(26) Bews, I. M.; Hayhurst, A. N.; Richardson, S. M.; Taylor, S. G. The order, Arrhenius parameters, and mechanism of the reaction between gaseous oxygen and solid carbon. Combust. Flame 2001, 124, 231-245. 